\title{
Oxidative Biphasic Depolymerization (BPD) of Kraft Lignin at Low pH
}

Dr. Saša Bjelić,* Dr. Luca Garbuio, ${ }^{[a]}$ Dr. Katarzyna R. Arturi, ${ }^{[a]}$ Prof. Dr. Jeroen A. van Bokhoven, ${ }^{[b, c]}$ Prof. Dr. Gunnar Jeschke, ${ }^{[d]}$ Prof. Dr. Frédéric Vogel ${ }^{[a, e]}$

\footnotetext{
${ }^{[a]}$ Bioenergy and Catalysis Laboratory, Energy and Environment Division, Paul Scherrer Institut, Forschungsstrasse 111, 5232 Villigen PSI, Switzerland

${ }^{[b]}$ Laboratory for Catalysis and Sustainable Chemistry, Energy and Environment Division, Paul Scherrer Institut, Forschungsstrasse 111, 5232 Villigen PSI, Switzerland

${ }^{\left[{ }^{[c]}\right.}$ ETH Zürich, Institute for Chemical and Bioengineering, Wolfgang-Pauli-Str. 10, 8093 Zürich, Switzerland

${ }^{[d]}$ ETH Zürich, Laboratory of Physical Chemistry, Wolfgang-Pauli-Str. 10, 8093 Zürich, Switzerland

${ }^{[\mathrm{e}]}$ University of Applied Sciences Northwestern Switzerland (FHNW), Bahnhofstrasse 6, 5210 Windisch, Switzerland

*Corresponding author, Laboratory for Bioenergy and Catalysis, Energy and Environment Division, Paul Scherrer Institute, Forschungsstrasse 111. 5232 Villigen PSI, Switzerland, e-mail: sasa.bjelic@psi.ch.
}

\begin{abstract}
In this work, we systematically investigated factors governing catalytic oxidation of Kraft lignin in a biphasic system at acidic conditions. The process is designated biphasic depolymerization (BPD) and is based on the concept of protective extraction of the target molecules from the reactive aqueous phase containing catalysts into an inert organic phase. The aim is to prevent over-oxidation, one of the main causes of decreased yields of high-value monomeric aromatics from depolymerization of lignin. Vanillin, a typical and commercially relevant product of lignin oxidation, was chosen as an indicator for understanding which factors impact the process. The conversion in water/octanol mixtures was shown to be more effective than in a monophasic system at corresponding conditions showing the proof of concept for BPD. A set of conversion conditions maximizing the yields of the target molecule was identified $\left(\mathrm{T}=170{ }^{\circ} \mathrm{C}, \mathrm{t}=60 \mathrm{~min}, \mathrm{pO} 2=5 \mathrm{MPa}\right)$. The presence of the oxidative catalyst (CUSO4) did not influence the conversion. The contributions of oxidation and acidolysis of lignin were assessed to be approx. 60 and $40 \%$, respectively. Based on the results, a strategy for optimizing BPD, a promising technique for valorization of technical lignins in acidic media, is laid out.

Keywords: Solvothermolysis; Vanillin; Oxidation; Valorization; Kraft lignin; Biphasic system.
\end{abstract}

This document is the accepted manuscript version of the following article:

Bjelić, S., Garbuio, L., Arturi, K. R., van Bokhoven, J. A., Jeschke, G., \& Voge1, F. (2018). Oxidative biphasic depolymerization (BPD) of kraft lignin at low pH. Chemistry select, 3(41), 11680-11686.

https://doi.org/10.1002/s1ct.201802877 


\section{Introduction}

Lignin remains the subject of intense research as it can be converted to green fuels and aromatic chemicals by a broad spectrum of conversion processes ${ }^{[1,2]}$. Lignin is a macro-molecule composed of substituted phenols linked through ether linkages and $\mathrm{C}-\mathrm{C}$ bonds ${ }^{[3]}$. Whereas the idea of breaking these bonds to gain the corresponding phenolic monomers is relatively simple, serious challenges are associated with its practical application. In a recent work summarizing the barriers towards a cost-effective biomass-to-biofuel valorization, lignin has been very aptly summarized as supramolecular self-assembled chaos ${ }^{[4]}$. First of all, the heterogeneity of lignin ${ }^{[5]}{ }_{L}$ in addition to the distribution of chemical bonds and functional groups ${ }^{[6]}$ render any chemo-selective process difficult, although advances in this direction have been achieved $\stackrel{[7-9]}{-}$. Another complication arises from the traditional methods used to extract lignin from the biomass ${ }^{[10]}$. They alter the structure of the protolignin, cleaving the labile $\beta$-O-4 linkages and increasing the density of the high dissociation energy carbon-carbon bonds, leading to a highly recalcitrant macro-molecular structure. As a consequence, the extracted lignin is less susceptible to chemical transformations required for valorization ${ }^{[11]}$. The most recent developments in tackling that challenge rely on the use of feedstocks in which lignin is modified by the means of chemical reactions with formaldehyde ${ }^{[12]}$ or by selective oxidation of the ether linkages $[7,9]$. The former approach is an effective pre-treatment method for unaltered lignins rich in $\beta-0-4$ moieties, which, upon hydrotreating, are converted into monomers with yields close to theoretical values ${ }^{[7,12]}$. However, the outlined approach is ineffective on extracted lignins such as Kraft lignin. In this case, the internal condensation already occurred during the extraction procedure, resulting in the high density of $\mathrm{C}-\mathrm{C}$ bonds, which, opposed to the ether linkages, are resilient to reductive upgrading with hydrogen. In order to break these bonds, severe conditions are required, e.g. high temperatures, which in turn leads to repolymerization of certain unstable reactive intermediates $[11,13]$. The repolymerization can be described as a cascade of reactions between lignin and its decomposition products, yielding high molecular weight species and solid products instead of high-value aromatic monomers ${ }^{[2,14]}$. The key to an efficient lignin valorization is thus a combination of high rates of depolymerization and preventing condensation of reaction products, and a broad spectrum of strategies have been applied for finding optima specific to certain conversion techniques ${ }^{[1]}$. Solvothermal depolymerization in water and organic solvents is an alternative valorization route to thermal techniques, such as pyrolysis, offering the potential to use significantly lower temperatures for lignin conversion thus minimizing the condensation phenomena ${ }^{[15}$. The

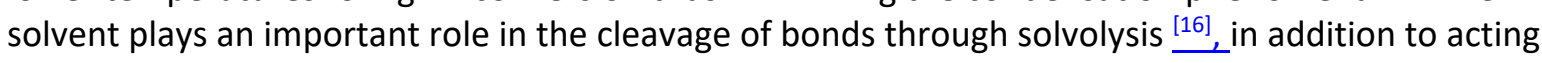
as a protecting agent for preventing side reactions among lignin fragments and reactive intermediates such as formaldehyde, Hibbert ketones, free phenols, epoxides, and aldehydes $\underline{[17-19]}$. In particular, supercritical ethanol (EtOH) enhances the yields of monomers in solvothermal experiments ${ }_{[20]}$. This beneficial effect was explained by observing that the reaction between the formed formaldehyde and $\mathrm{EtOH}$ competes efficiently with the side-reactions between the formaldehyde and the lignin monomers, which are responsible for the oligomerization of lignin products. Additionally, EtOH acts as a capping agent by alkylating the free $\mathrm{OH}$-groups and aromatic rings of phenols in lignin ${ }^{[20,21]}$. Numerous other organic solvents of varying polarity have been applied for the same purpose ${ }^{[1]}$. Despite the promising findings, the commercial relevance of ligninderived monomers, such as vanillin, remains relatively low in most processes. While oxidative depolymerization has been proposed as an effective method towards increasing the yields of vanillin by supporting the hydrolysis of ether bonds with the cleavage of the more stable $\mathrm{C}-\mathrm{C}$ bonds, thermal conversion in immiscible water/organic solvent two-phase mixtures is a promising strategy for suppressing over-oxidation of the target molecules. The oxidative biphasic depolymerization (BPD) method aims at effective catalytic conversion of the feedstocks into high-value products followed by their stabilization through a continuous, selective, solubility-driven extraction into an inert organic 
phase. Similar methodology has been studied extensively by Dumesic and co-workers for the dehydration of carbohydrate feedstocks to key biorefinery chemicals, e.g. HMF, furfural, and levulinic acid, in the presence of butanol, methyl isobutyl ketone, alkylphenols, and DMSO ${ }^{[22-27]}$. The results show that conversion rates of $95 \%$ can be obtained along with just as high selectivities (>85 \%) ${ }^{[1]}$. The literature regarding the application of BPD on lignin is limited in both scope and extent. A recent review on lignin valorization by Schutyser et al. ${ }^{[1]}$ revealed the overwhelming heterogeneity of the lignin conversion field. Although the authors discuss a vast number of transformation techniques and refer to over 600 publications, the concept of BPD is not covered, showing how novel and unexplored this valorization strategy is. In a patent from 1974 to American Cyanamid Co., either benzene or diphenyl were added to spent sulfite liquor before the thermal conversion aiming for increasing vanillin yields ${ }^{[28]}$. Yoshikawa et al. ${ }^{[29]}$ used a water/butanol solvent system with a silica-alumina catalyst at $200-350^{\circ} \mathrm{C}$. They observed that the organic alcohol was able to efficiently extract phenolic products and increase the overall monomer yields. However, neither in the former nor in the latter study were the actual yields of any monomeric products provided. Cai et al. [30] studied a reversed-phase conversion of organosolv lignin in a water/butanol system in the presence of ionic liquids and demonstrated a significant increase in yield.

In the current study, we propose an innovative BPD scheme for producing vanillin from Kraft lignin. With 100 million tons produced worldwide, industrial lignins represent a significant resource and the overall sustainability of biomass as a source of fuels, chemicals, and materials will depend on our ability to maximize the lignin value-chain and the full integration of the lignin platform into the future biorefinery. Vanillin yield was chosen as the conversion's main indicator, and an unambiguous procedure for vanillin quantification was developed. Vanillin is well known for its use as a flavoring agent, as well as a potential key-intermediate of biobased polymers ${ }^{[1,32]}$. It was the first chemical targeted by scientists since the potential of lignin was recognized in the early 20th century, with several patents filed between the $1940 \mathrm{~s}$ and $1970 \mathrm{~s} 28,33-37]$. The proposed process involves a mild catalytic oxidation at low $\mathrm{pH}$, which combines acid-enhanced hydrolysis of ether bonds with cleaving the recalcitrant $\mathrm{C}-\mathrm{C}$ bonds by molecular oxygen. 1-octanol was employed as the primary organic solvent and extraction phase due to its low solubility in water $\left(0.05 \mathrm{wt} . \%\right.$ at $\left.20^{\circ} \mathrm{C}\right)$, high boiling point $\left(\mathrm{bp}=195^{\circ} \mathrm{C}\right)$, thermal stability, and high solubility of vanillin $\left(10 \mathrm{~g} / \mathrm{L}\right.$ in water at $20^{\circ} \mathrm{C}$ but one order of magnitude higher in alcohols) ${ }^{[38]}$. The conversion was studied as a function of selected physical and chemical process parameters aiming at elucidation of its most basic mechanistic aspects, including the effects of temperature, reaction time, the supply of the oxidant, and the presence of a catalyst.

\section{Results and Discussion}

\subsection{Proof of concept}

The concept of oxidative biphasic depolymerization (BPD), which is a combination of acid-catalyzed reactions as well as mild oxidative pathways, is outlined schematically in Figure 1. 


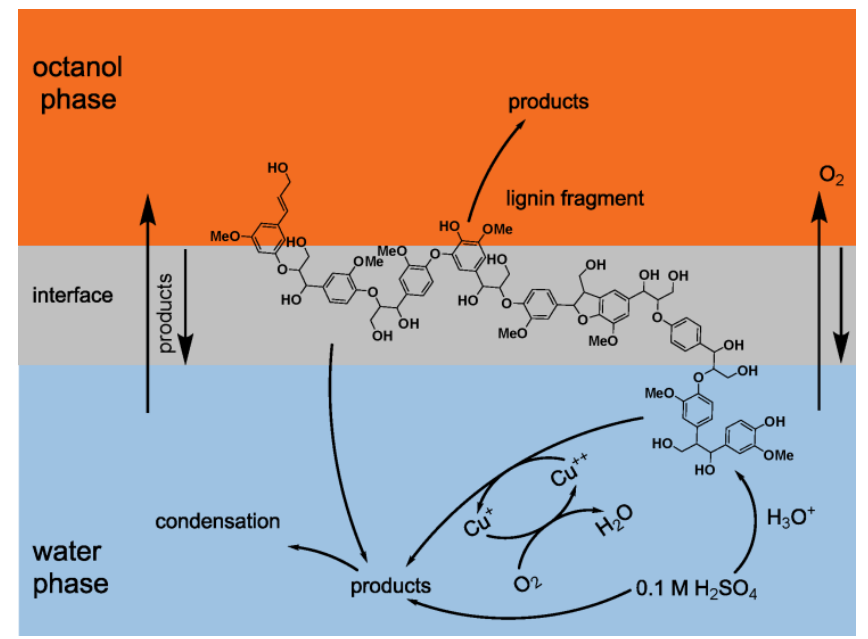

Figure 1: Schematic representation of the liquid-liquid two-phase system. Depolymerization reactions occur in the water phase and products are extracted into the octanol phase. $\mathrm{Cu}(\mathrm{II})$ and protons are preferentially solvated in the water phase. The solubility of oxygen (at $0.1 \mathrm{MPa}, 293 \mathrm{~K}$ ) is $40 \mathrm{mg} / \mathrm{L}$ and $\approx 230 \mathrm{mg} / \mathrm{L}$ in pure water and octanol, respectively $\underline{[59]}$.

Both the $\mathrm{CuSO}_{4}$ catalyst and protons were present in the water phase. Their role was to promote the oxidation and hydrolysis of lignin, respectively. It was anticipated that the cleavage of ether bonds would take place in a multi-step acidolysis reaction on the water/octanol interface where the polar parts of the lignin macro molecule are exposed to the reactive environment. Figure $\underline{2}$ demonstrates the appearance of the biphasic system at room temperature before (left) and after the reaction (right).

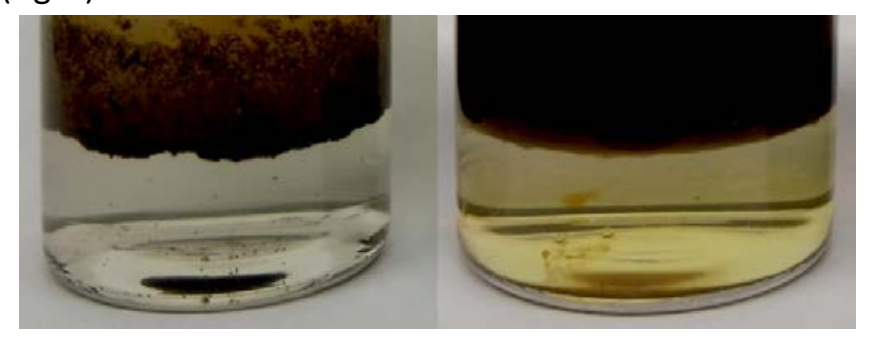

Figure 2: Photographs of the starting systems and of oils obtained after solvothermal treatment of Indulin AT in the two-phase system. Before the reaction (left), lignin is mostly present as a suspension at the interface between water (bottom layer) and 1-octanol (top layer). Fine particles of lignin are additionally suspended in the more viscous octanol solvent and stick to the glass vial. After solvothermolysis (right), most of the products are concentrated in the octanol phase.

Mixing water with octanol positioned the semipolar amphiphilic lignin with limited solubility at $\mathrm{pH}=$ 1 at the interface between the phases. The concept of this system was to create a stable octanolaqueous biphasic system for conversion in the hydrothermal medium containing a catalyst with an effective control of the reaction pathways by continuous removal, as well as an easy, phase-based separation of the products. The low $\mathrm{pH}$ was selected to promote the effective depolymerization, as previously described by Rudolf von Rohr and co-workers ${ }^{[39,40]}$, as well as the transfer of the formed vanillin into the organic phase. The results obtained in this study clearly demonstrate the proof of concept for BPD. As can be observed from the image of the reaction mixture after the reaction, the octanol phase was the main sink for the phenolic conversion products from lignin. Furthermore, the 
yields of vanillin $\left(Y_{v}\right)$ increased more than sixfold ( $Y_{v}$ from 0.17 to 1.11 wt.\%) by the application of the biphasic system $\left(R_{a}\right)$ compared to the monophasic conversion $\left(R_{j}\right)$ at standard conditions $(10 \mathrm{~g} / \mathrm{l}$ lignin, $\mathrm{T}=170{ }^{\circ} \mathrm{C}, \mathrm{p}=0.5 \mathrm{MPa} \mathrm{O}_{2}, \mathrm{t}=40 \mathrm{~min}, 5 \mathrm{mM} \mathrm{Cu}^{2+}$ ). The overall yields from the biphasic experiments in this study varied in range 0.03-0.13 wt.\% and 0.43-1.30 wt.\% for the aqueous and octanol phases, respectively (Table $\underline{1,}$ Figure $\underline{4}$, and Figure $\underline{5 \text { ). }}$ 
Table 1: Summary of tested experimental parameters in the solvothermal experiments and corresponding vanillin yields obtained from the solvothermal experiments. W: water monophasic system; W/O: water/octanol biphasic system; W/X: water/p-xylene biphasic system.

Experimental conditions

\begin{tabular}{|c|c|c|c|c|c|c|}
\hline Run & Conditions & $\begin{array}{l}\text { Lignin } \\
{[\mathrm{g} / \mathrm{I}]}\end{array}$ & $\mathrm{T}[\mathrm{C}]$ & $\mathrm{p}[\mathrm{MPa}]$ & $\begin{array}{c}\mathrm{t} \\
{[\mathrm{min}]}\end{array}$ & Solvent \\
\hline
\end{tabular}

\begin{tabular}{|c|c|c|c|c|c|c|c|c|}
\hline $\mathrm{Ra}$ & Standard & 10 & 170 & 0.5 & $\mathrm{O}_{2}$ & 40 & $\mathrm{~W} / \mathrm{O}$ & 5 \\
\hline $\mathrm{R}_{\mathrm{b}}$ & Catalyst & 10 & 170 & 0.5 & $\mathrm{O}_{2}$ & 40 & $\mathrm{~W} / \mathrm{O}$ & 0 \\
\hline $\mathrm{R}_{\mathrm{c}}$ & & 10 & 170 & 0.5 & $\mathrm{O}_{2}$ & 40 & $\mathrm{~W} / \mathrm{O}$ & 20 \\
\hline $\mathrm{R}_{\mathrm{d}}$ & & 10 & 170 & 0.5 & $\mathrm{O}_{2}$ & 40 & $\mathrm{~W} / \mathrm{O}$ & $\mathrm{CuO}$ \\
\hline $\mathrm{R}_{\mathrm{e}}$ & Lignin & 1 & 170 & 0.5 & $\mathrm{O}_{2}$ & 40 & $\mathrm{~W} / \mathrm{O}$ & 5 \\
\hline$R_{f}$ & Pressure & 10 & 170 & 0.5 & Air & 40 & $\mathrm{~W} / \mathrm{O}$ & 5 \\
\hline $\mathrm{R}_{\mathrm{g}}$ & & 10 & 170 & 0.9 & $\mathrm{O}_{2}$ & 40 & $\mathrm{w} / \mathrm{O}$ & 5 \\
\hline $\mathrm{R}_{\mathrm{h}}$ & & 10 & 170 & 0.5 & $\mathrm{Ar}$ & 40 & $\mathrm{~W} / \mathrm{O}$ & 5 \\
\hline $\mathrm{R}_{\mathrm{i}}$ & Solvent & 10 & 170 & 0.5 & $\mathrm{O}_{2}$ & 40 & $w / x$ & 5 \\
\hline $\mathrm{R}_{\mathrm{j}}$ & & 10 & 170 & 0.5 & $\mathrm{O}_{2}$ & 40 & W & 5 \\
\hline $\mathrm{R}_{\mathrm{k}}$ & Temperature & 10 & 140 & 0.5 & $\mathrm{O}_{2}$ & 40 & $\mathrm{~W} / \mathrm{O}$ & 5 \\
\hline $\mathrm{R}_{\mathrm{I}}$ & & 10 & 200 & 0.5 & $\mathrm{O}_{2}$ & 40 & $\mathrm{~W} / \mathrm{O}$ & 5 \\
\hline $\mathrm{R}_{\mathrm{m}}$ & Time & 10 & 170 & 0.5 & $\mathrm{O}_{2}$ & 15 & $\mathrm{~W} / \mathrm{O}$ & 5 \\
\hline $\mathrm{R}_{\mathrm{n}}$ & & 10 & 170 & 0.5 & $\mathrm{O}_{2}$ & 60 & $\mathrm{~W} / \mathrm{O}$ & 5 \\
\hline $\mathrm{R}_{\mathrm{o}}$ & & 10 & 170 & 0.5 & $\mathrm{O}_{2}$ & 120 & $\mathrm{w} / \mathrm{O}$ & 5 \\
\hline
\end{tabular}

\begin{tabular}{|c|c|c|c|c|c|c|c|}
\hline \multicolumn{8}{|c|}{ Obtained yields } \\
\hline \multirow{3}{*}{ Run } & \multicolumn{3}{|c|}{ Organic phase } & \multicolumn{3}{|c|}{ Aqueous phase } & \multirow{2}{*}{$\begin{array}{c}\text { Total } \\
\mathrm{Y}_{\mathrm{v}}\end{array}$} \\
\hline & c & c & Yv & c & c & $Y_{v}$ & \\
\hline & {$[\mathrm{M}]$} & {$[\mathrm{g} / \mathrm{I}]$} & [wt.\%] & {$[\mathrm{M}]$} & {$[\mathrm{g} / \mathrm{l}]$} & [wt.\%] & [wt.\%] \\
\hline $\mathrm{Ra}$ & 145.1 & 0.221 & 1.06 & 7.1 & 0.01 & 0.05 & 1.11 \\
\hline $\mathrm{R}_{\mathrm{b}}$ & 74.8 & 0.115 & 0.78 & 5.2 & 0.007 & 0.05 & 0.83 \\
\hline $\mathrm{R}_{\mathrm{c}}$ & 92.8 & 0.134 & 0.91 & 4.9 & 0.007 & 0.05 & 0.96 \\
\hline$R_{d}$ & 103 & 0.146 & 0.85 & 10.9 & 0.017 & 0.1 & 0.95 \\
\hline $\mathrm{R}_{\mathrm{e}}$ & 21.4 & 0.032 & 1.76 & 0.6 & 0.001 & 0.05 & 1.81 \\
\hline $\mathrm{R}_{\mathrm{f}}$ & 68.9 & 0.101 & 0.7 & 5 & 0.006 & 0.04 & 0.74 \\
\hline $\mathrm{R}_{\mathrm{g}}$ & 115 & 0.166 & 1.15 & 6.5 & 0.009 & 0.06 & 1.21 \\
\hline $\mathrm{R}_{\mathrm{h}}$ & 42.4 & 0.064 & 0.43 & 3.3 & 0.004 & 0.03 & 0.46 \\
\hline $\mathrm{R}_{\mathrm{i}}$ & 75.3 & 0.103 & 0.47 & 34 & 0.046 & 0.21 & 0.68 \\
\hline $\mathrm{R}_{\mathrm{j}}$ & - & - & - & 0.9 & 0.002 & 0.17 & 0.17 \\
\hline $\mathrm{R}_{\mathrm{k}}$ & 55 & 0.083 & 0.58 & 3.3 & 0.005 & 0.03 & 0.61 \\
\hline $\mathrm{R}_{\mathrm{l}}$ & 8.2 & 0.012 & 0.08 & 0.5 & 0.001 & 0 & 0.08 \\
\hline
\end{tabular}




\begin{tabular}{l|ccc|ccc|c}
$\mathrm{R}_{\mathrm{m}}$ & 50.3 & 0.074 & 0.51 & 3.1 & 0.004 & 0.03 & 0.54 \\
$\mathrm{R}_{\mathrm{n}}$ & 129.5 & 0.188 & 1.3 & 13.4 & 0.018 & 0.13 & 1.43 \\
$\mathrm{R}_{\mathrm{o}}$ & 104.2 & 0.159 & 1.06 & 5.8 & 0.008 & 0.05 & 1.11 \\
\hline
\end{tabular}




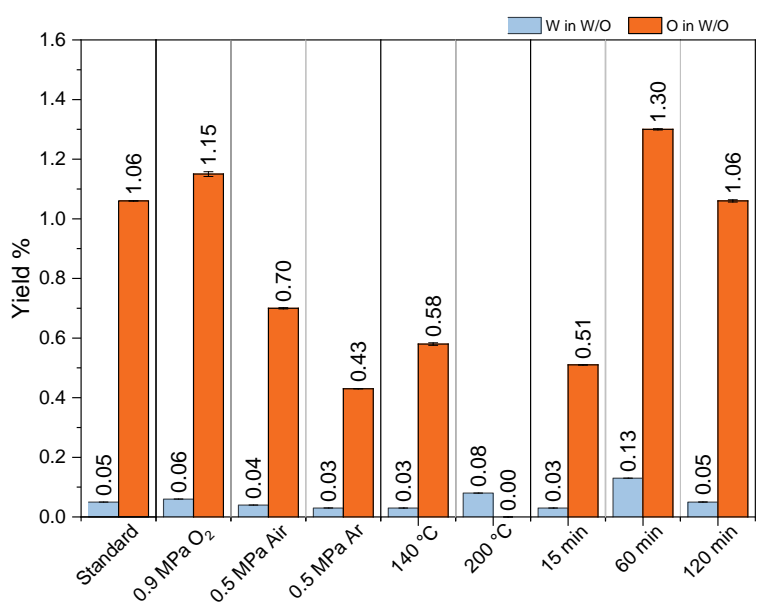

Figure 3: Vanillin yields from Indulin AT obtained by testing several physical parameters. Standard: $170^{\circ} \mathrm{C}, 0.5 \mathrm{MPa}$ of initial oxygen pressure, $500 \mathrm{rpm}$ mixing, 40 minutes reaction time, $5 \mathrm{mM} \mathrm{Cu}$ (II) and $0.1 \mathrm{M} \mathrm{H}_{2} \mathrm{SO}_{4}$ in $5 \mathrm{~mL}$ water, 5 $\mathrm{mL}$ octanol, $10 \mathrm{~g} / \mathrm{L}$ of Indulin AT. Note: in most cases error bars are small and thus invisible in the graph.

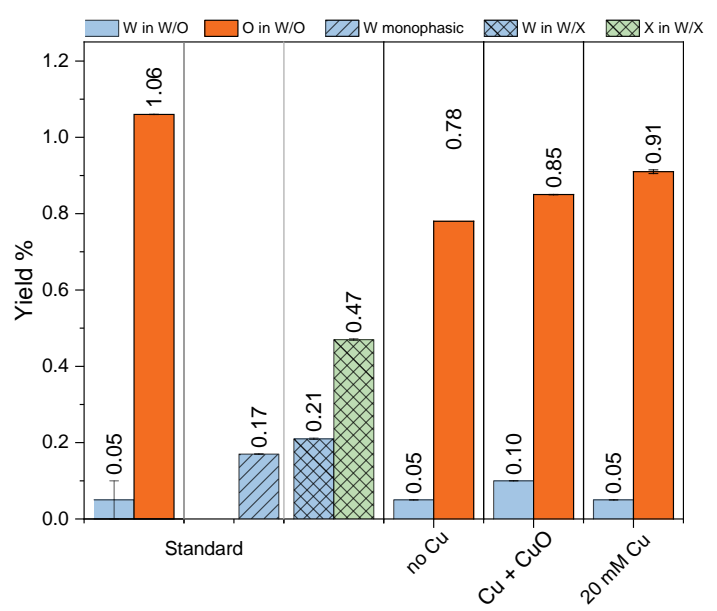

Figure 4: Vanillin yields from Indulin AT obtained by testing several chemical parameters. Standard: $170{ }^{\circ} \mathrm{C}, 0.5 \mathrm{MPa}$ of initial oxygen pressure, $500 \mathrm{rpm}$ mixing, 40 minutes reaction time, $5 \mathrm{mM} \mathrm{Cu}(\mathrm{II})$ and $0.1 \mathrm{M} \mathrm{H}_{2} \mathrm{SO}_{4}$ in $5 \mathrm{~mL}$ water (W), $5 \mathrm{~mL}$ octanol (O), $10 \mathrm{~g} / \mathrm{L}$ of Indulin AT. Yields were rounded to 2 digits after the comma. Monophasic systems are represented by a diagonally hatched pattern. The two-phase system with water/p-xylene $(X)$ is in blue and green, respectively. There is no significant increase of the vanillin yield after addition of the oxidative catalyst $\left(\mathrm{CuSO}_{4}\right.$ or $\left.\mathrm{CuO}\right)$ observable. Note: in most cases error bars are small and thus invisible in the graph.

\subsection{Influence of parameters}

Studies of the effects of physical and chemical parameters indicated several interesting trends in BPD. The optimal temperature was identified at $\mathrm{T}=170{ }^{\circ} \mathrm{C}$, 
indicating slow depolymerization and increased repolymerization at $\mathrm{T}=140{ }^{\circ} \mathrm{C}$ and $\mathrm{T}=$ $200{ }^{\circ} \mathrm{C}$, respectively. The presence of the homogeneous catalyst, $\mathrm{CuSO}_{4}$, which aimed at promotion of $\mathrm{C}-\mathrm{C}$ bond cleavage by oxygen, led to a small, but constant throughout the studied range of $\mathrm{CuSO}_{4}$ concentrations, increase in yields. The presence of copper as a heterogeneous catalyst in the form of CuO slightly increased the yields of vanillin in the aqueous fraction ( $Y_{v}$ from 0.05 to $0.10 \mathrm{wt} . \%$ ). The reasons for the latter trend are not immediately obvious. It was clear, however, that $\mathrm{O} 2$ was the main oxidizing agent in the conversion. Production of vanillin under argon atmosphere $\left(Y_{v}=0.46\right.$ wt.\%) was due to hydrolysis of ether moieties, while addition of oxygen resulted in an additional oxidation-based yield of $0.60 \mathrm{wt} . \%$. See Section 2.3 for a detailed discussion of this phenomenon. Replacing octanol with $p$-xylene in $R_{i}$, an organic solvent exhibiting excellent solubility for aromatic products but lacking the alcohol functionality necessary for scavenging of reactive intermediates, a vanillin yield of 0.7 wt.\% was measured. This value is four times higher than the yield obtained with the one-phase water system $\left(R_{j}\right)$, but only half the value obtained with the water-octanol system $\left(R_{a}\right)$. This proves $p$-xylene's capability towards protective extraction of vanillin, as well clearly demonstrates that octanol's role in the designed BPD reaches beyond the extractive mechanism, most probably into a capping-agent function. Also, we observed that yields improve when reducing lignin concentration by a factor of 10 , indicating either mass transport or kinetic barriers preventing effective depolymerization. While using air instead of pure oxygen the yields decreased, increasing the pure oxygen pressure had the opposite effect. The yield rose from 0.46 wt.\% to 0.74 wt.\% when going from $0 \mathrm{MPa}$ to $0.5 \mathrm{MPa} \mathrm{O}_{2}$ partial pressure, because the higher $\mathrm{O}_{2}$ partial pressure increases $\mathrm{O}_{2}$ concentration in the solution. A further increase to $0.9 \mathrm{MPa}$ improved yields further to $1.21 \mathrm{wt} . \%$, meaning that the available oxygen is an important factor in lignin depolymerization to vanillin. An optimal conversion time was obtained at $\mathrm{t}=60 \mathrm{~min}$, showing a parabolic dependence between $t=15,40,60$, and $120 \mathrm{~min}$. While the increasing yield as a function of reaction time indicated an accumulation of vanillin in octanol, the following decrease in the values demonstrated its loss by subsequent transformations, either oxidation or condensation. The applied reaction conditions were favorable for opening the aromatic rings and converting the intermediates into aliphatic carboxylic acids [1].

\subsection{Theoretical yield assessment}

G-units present in lignin are the precursors of vanillin (Figure 5), and the conversion of the former into the latter during BPD was a combination of acidic hydrolysis of $\beta$-O-4 linkages and oxidation of the recalcitrant $\mathrm{C}-\mathrm{C}$ bonds. 


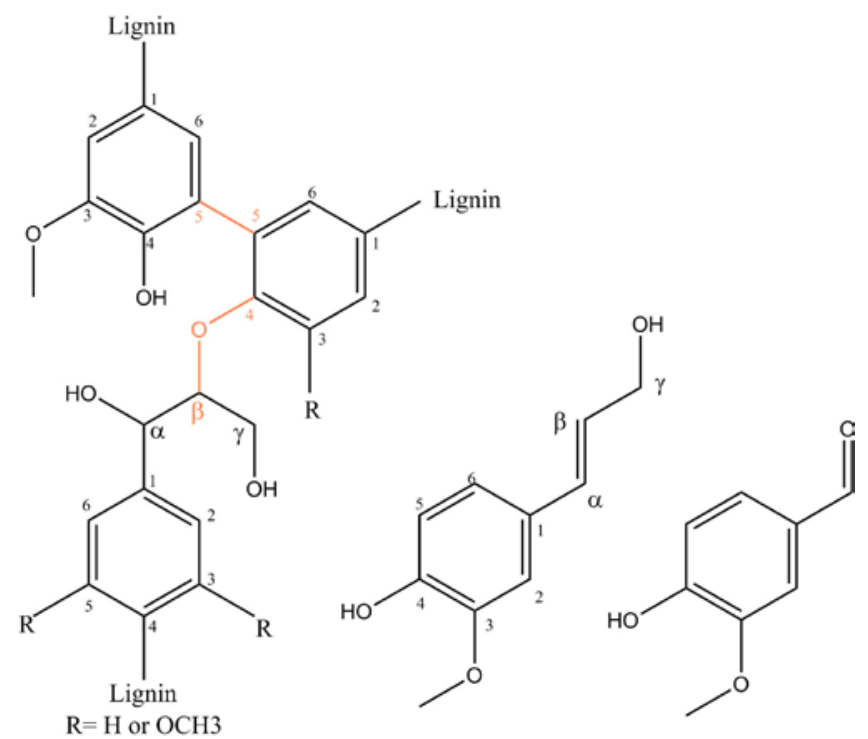

Figure 5: Typical units in Kraft lignin (left) with the most common ether ( $\beta-\mathrm{O}-4)$ and carbon (5-5) bonds outlined; G-unit structure (middle); and vanillin (right).

Acidic oxidation, which has been studied in detail in the literature $[1,41]$, starts by the removal of hydroxy groups from the $C_{a}$, resulting in a benzylic carbenium ion intermediate. This is followed by the cleavage of the $C_{\beta}-C_{Y}$ bond and the release of formaldehyde and an enol ether [41-43]. The subsequent hydrolysis of the enols results in the formation of direct vanillin precursors [1]. If all $\beta$-O-4 bonding all G-units in Kraft lignin were hydrolyzable, the yields of vanillin would be in range $30-46 \mathrm{wt} . \%$. However, obtaining such high yields is hindered by the presence of recalcitrant $\mathrm{C}-\mathrm{C}$ bonds cross-linking the precursors. Only free phenolic $\mathrm{G}$-units, i.e. the units attached to the lignin macro-molecule by a $\beta$-O-4 linkage at the $C_{1}$ position; neither alkylated, nor otherwise cross-linked, are susceptible to hydrolysis [44-46]. An empirical correlation between the yields of monomeric products and the square of the amount of hydrolysable $\beta$-O-4 linkages, as described by Eq. 1 , has been observed for different types of lignin and conversion processes $[1,2,46,47]$

$$
\mathrm{Ya} \approx[\beta-O-4]^{2}(1)
$$

$[\beta-O-4]$ is defined as the number of ether linkages per 100 aromatic units. In Kraft lignin, $[\beta-O-4]$ was found to be rather scarce, namely 7 linkages per 100 aromatic units (corresponding to $0.07 \mathrm{~mol} / \mathrm{mol}$ ) [1]. Thus the maximum obtainable monomer yield of 0.49 mol\% is in accordance with the vanillin yield of $0.46 \mathrm{~mol} \%$ obtained in this study in argon atmosphere. In this particular case, wt.\% can be expressed as mol\%, since vanillin corresponds to one aromatic unit. Acidic hydrolysis was responsible for approx. half of the conversion with oxidative scission of $\mathrm{C}-\mathrm{C}$ bonds increasing the yield of the monomeric products, as previously reported in the literature $[48,49]$. The process is driven by an electrophilic attack of oxygen on the sites of high electron density in lignin (ortho- and para-positions, as well as $\mathrm{C}_{\beta}$ atoms) [1]. The reported values were in agreement with previously obtained results, indicating an approx. 1:1 conversion contribution ratio for hydrolysis and oxidation $[42,50]$. 
Commercial biomass-based vanillin is typically recovered by oxidative treatment of spent liquor from the calcium sulphite pulping process under strong alkaline conditions. The process, currently performed exclusively by Borregaard AS, achieves a vanillin yield of about $1 \mathrm{wt} . \%$ with respect to the lignin content and covers approx. $15 \%$ of the total world demand [51]. At the laboratory scale, methods using $\mathrm{O}_{2}$ as oxidant (in pure form or as the component in the air) have been developed for vanillin production and yields in the range $1.5-10.8 \mathrm{wt} . \%$ have been reported [39, 40, 48, 49, 51-57]. The yields obtained in this study seem fairly low compared to studies at similar conditions in monophasic systems: 1 wt.\% in this study vs. $\approx 3$ wt.\% according to Zhang et al. [54]. Voitl and Rudolf von Rohr [39] reported a vanillin yield of $1.18 \mathrm{wt}$.\% using Kraft lignin in water at $\mathrm{pH} 1$. Under the same conditions $\left(170{ }^{\circ} \mathrm{C}, 0.5 \mathrm{MPa}\right.$ of initial oxygen pressure, 40 minutes total reaction time, $0.1 \mathrm{M} \mathrm{H}_{2} \mathrm{SO}_{4}$ in water, and $10 \mathrm{~g} / \mathrm{L}$ of Kraft lignin from Aldrich), we measured a yield of $0.17 \mathrm{wt} . \%$. A significant difference between those two studies was the method for oxidant delivery. While in the current study, we applied a magnetic stirrer and the amount of oxygen available for the reaction was limited by the amount of dissolved $\mathrm{O}_{2}$ and by its diffusion from the gas into the liquid phase, Voitl and Rudolf von Rohr [39] used a gassing stirrer combining rapid mixing with faster oxygen transfer into the water phase. Furtermore, small effective reactive interfacial area combined with shielding of the lignin chains from the reactive surfaces may have been a limiting factor. As it was observed in run $R_{e}$, the yields improved when reducing lignin concentration by a factor of 10 , which could indicate a competition on the interface for reactive oxygen species.

\section{Conclusions}

In this study, we examined factors governing production of vanillin from Kraft lignin by means of the oxidative biphasic depolymerization at low $\mathrm{pH}$, a process based on the concept of protective extraction of high-value target molecules from a reactive aqueous phase into an inert organic phase thus preventing their over-oxidation. The aim was to explore and understand the fundamental aspects of BPD, especially its limitations and bottlenecks. The results showed that the organic phase was the main product sink thus clearly demonstrating the proof of concept for depolymerization of lignin by BPD. The use of water/octanol biphasic system resulted in more than six-fold increase of vanillin yields compared to the corresponding monophasic system, the increase due to the stabilization of the target product via extraction, and possibly a capping effect. Contributions of oxidation and acidolysis for the production of vanillin was approx. 60 and $40 \%$, respectively. Thus, while $\mathrm{O}_{2}$ was the main driver behind the formation of vanillin, hydrolysis of the ether bonds was not without significance. The yields of vanillin obtained in this study have been limited by the applied experimental setup, in particular the inefficient oxygen transfer and low interfactial area between the phases. The optimization of BPD should therefore focus on oxidant management, as well as selection of catalysts promoting oxidation at low $\mathrm{pH}$, and maximizing the interphase reaction area. Strategies involving application of salts, nanoparticles, and ionic liquids to form a stable two-phase emulsions have been described in the literature [30, $58]$, and could be of use in optimization of BPD of lignin.

\section{Supporting Information Summary}


Experimental details, calibration curve for vanillin quantication, extracted ion chromatogram (XIC) of vanillin and 13C-vanillin, and Variation in the LC-MS/MS area over time for the vanillin signal at acidic conditions are available in SI.

\section{Acknowledgments}

This work was supported by the Swiss National Science Foundation (SNF) as part of NRP66 Resource Wood under grant number 406640-136892. This research project is financially supported by the Swiss Innovation Agency Innosuisse and is part of the Swiss Competence Center for Energy Research SCCER BIOSWEET. Part of this work was supported by and performed within the Energy System Integration Platform at PSI. The authors would also like to thank Marc-Olivier Ebert and Christian Bährle for fruitful discussions.

\section{Keywords}

Biphasic system; Kraft lignin; Oxidation; Solvothermolysis; Valorization; Vanillin 


\section{References}

[1] W. Schutyser, T. Renders, S. Van den Bosch, S.-F. Koelewijn, G. T. Beckham, B. F. Sels, Chem. Soc. Rev. 2018, 47, 852-908.

[2] R. Rinaldi, R. Jastrzebski, M. T. Clough, J. Ralph, M. Kennema, P. C. Bruijnincx, B. M. Weckhuysen, Angew. Chem. Int. Edit. 2016, 55, 8164-8215.

[3] J. Zakzeski, P. C. Bruijnincx, A. L. Jongerius, B. M. Weckhuysen, Chem. Rev. 2010, 110, 3552-3599.

[4] K. E. Achyuthan, A. M. Achyuthan, P. D. Adams, S. M. Dirk, J. C. Harper, B. A. Simmons, A. K. Singh, Molecules 2010, 15, 8641-8688.

[5] P. Azadi, O. R. Inderwildi, R. Farnood, D. A. King, Renew. Sust. Energ. Rev. 2013, 21, 506-523.

[6] R. Parthasarathi, R. A. Romero, A. Redondo, S. Gnanakaran, J. Phys. Chem. Lett. 2011, 2, 26602666.

[7] A. Rahimi, A. Azarpira, H. Kim, J. Ralph, S. S. Stahl, J. Am. Chem. Soc. 2013, 135, 6415-6418.

[8] P. J. Deuss, M. Scott, F. Tran, N. J. Westwood, J. G. de Vries, K. Barta, J. Am. Chem. Soc. 2015, 137, 7456-7467.

[9] C. S. Lancefield, O. S. Ojo, F. Tran, N. J. Westwood, Angew. Chem. Int. Edit. 2015, 54, $258-262$.

[10] L. da Costa Sousa, S. P. Chundawat, V. Balan, B. E. Dale, Curr. Opin. Biotech. 2009, 20, 339-347.

[11] C. Bährle, V. Custodis, G. Jeschke, J. A. van Bokhoven, F. Vogel, ChemSusChem 2014, 7, $2022-2029$.

[12] L. Shuai, M. T. Amiri, Y. M. Questell-Santiago, F. Héroguel, Y. Li, H. Kim, R. Meilan, C. Chapple, J. Ralph, J. S. Luterbacher, Science 2016, 354, 329-333.

[13] S. Kim, S. C. Chmely, M. R. Nimlos, Y. J. Bomble, T. D. Foust, R. S. Paton, G. T. Beckham, J. Phys. Chem. Lett. 2011, 2, 2846-2852.

[14] C. Li, X. Zhao, A. Wang, G. W. Huber, T. Zhang, Chem. Rev 2015, 115, 11559-11624.

[15] A. A. Peterson, F. Vogel, R. P. Lachance, M. Fröling, M. J. Antal Jr, J. W. Tester, Energ. Environ. Sci. 2008, 1, 32-65.

[16] L. Shuai, J. Luterbacher, ChemSusChem 2016, 9, 133-155.

[17] M. Saisu, T. Sato, M. Watanabe, T. Adschiri, K. Arai, Energ. Fuel. 2003, 17, 922-928.

[18] A. Toledano, L. Serrano, J. Labidi, Fuel 2014, 116, 617-624.

[19] J. S. Luterbacher, A. Azarpira, A. H. Motagamwala, F. Lu, J. Ralph, J. A. Dumesic, Energ. Environ. Sci. 2015, 8, 2657-2663.

[20] X. Huang, T. I. Korányi, M. D. Boot, E. J. Hensen, Green Chem. 2015, 17, 4941-4950.

[21] X. Huang, T. I. Korányi, M. D. Boot, E. J. Hensen, ChemSusChem 2014, 7, 2276-2288.

[22] B. Kuster, H. Der Van Steen, Starch-Starke 1977, 29, 99-103.

[23] Y. Román-Leshkov, J. A. Dumesic, Top. Catal. 2009, 52, 297-303.

[24] E. I. Gürbüz, S. G. Wettstein, J. A. Dumesic, ChemSusChem 2012, 5, 383-387.

[25] Y. Román-Leshkov, J. N. Chheda, J. A. Dumesic, Science 2006, 312, 1933-1937.

[26] J. C. Serrano-Ruiz, J. A. Dumesic, Energ. Environ. Sci. 2011, 4, 83-99.

[27] Q. P. Peniston, Manufacture of 5-hydroxymethyl 2-furfural, 1956, US Patent 2,750,394.

[28] C. Yang, Process for the manufacture of vanillin from sulfite waste liquor, 1974, US Patent 3,790,637. 
[29] T. Yoshikawa, T. Yagi, S. Shinohara, T. Fukunaga, Y. Nakasaka, T. Tago, T. Masuda, Fuel Process. Technol. 2013, 108, 69-75.

[30] Z. Cai, Y. Li, H. He, Q. Zeng, J. Long, L. Wang, X. Li, Ind. Eng. Chem. Res. 2015, 54, 11501-11510.

[31] A. Van, K. Chiou, H. Ishida, Polymer 2014, 55, 1443-1451.

[32] M. Fache, B. Boutevin, S. Caillol, Eur. Polym. J. 2015, 68, 488-502.

[33] L. T. Sandborn, S. J. Richter, H. G. Clemens, Process of making vanillin, 1936, US Patent 2,057,117.

[34] F. J. Henry, M. H. Borden, Method of producing vanillin, 1951, US Patent 2,576,752.

[35] M. H. Borden, S. C. Alfred, Method of producing vanillin, 1950, US Patent 2,516,827.

[36] C. C. Bryan, Manufacture of vanillin from lignin, 1954, US Patent 2,692,291.

[37] C. David, C. D. Logan, Method of producing vanillin and other useful products from lignosulfonic acid compounds, 1962, US Patent 3,054,659.

[38] F. Shakeel, N. Haq, N. A. Siddiqui, Food Chem. 2015, 180, 244-248.

[39] T. Voitl, P. Rudolf von Rohr, ChemSusChem 2008, 1, 763-769.

[40] H. Werhan, J. M. Mir, T. Voitl, P. Rudolf von Rohr, Holzforschung 2011, 65, 703-709.

[41] T. Yokoyama, J. Wood Chem. Technol. 2015, 35, 27-42.

[42] M. R. Sturgeon, S. Kim, K. Lawrence, R. S. Paton, S. C. Chmely, M. Nimlos, T. D. Foust, G. T. Beckham, ACS Sustain. Chem. Eng. 2013, 2, 472-485.

[43] T. Imai, T. Yokoyama, Y. Matsumoto, J. Wood Sci. 2011, 57, 219-225.

[44] A. Guerra, I. Filpponen, L. A. Lucia, D. S. Argyropoulos, J. Agr. Food Chem. 2006, 54, 9696-9705.

[45] P. Sannigrahi, A. J. Ragauskas, S. J. Miller, Bioenerg. Res. 2008, 1, 205-214.

[46] S. Constant, H. L. Wienk, A. E. Frissen, P. de Peinder, R. Boelens, D. S. Van Es, R. J. Grisel, B. M. Weckhuysen, W. J. Huijgen, R. J. Gosselink, et al., Green Chem. 2016, $18,2651-2665$.

[47] S. Van den Bosch, W. Schutyser, R. Vanholme, T. Driessen, S.-F. Koelewijn, T. Renders, B. De Meester, W. Huijgen,

W. Dehaen, C. Courtin, et al., Energ. Environ. Sci. 2015, 8, 1748-1763.

[48] F. Bjorsvik, Hans-Rene; Minisci, Org. Process Res. Dev. 1999, 3, 330-340.

[49] Q. Xiang, Y. Lee in Twenty-Second Symposium on Biotechnology for Fuels and Chemicals, Springer, pp. 7180.

[50] A. W. Pacek, P. Ding, M. Garrett, G. Sheldrake, A. W. Nienow, Ind. Eng. Chem. Res. 2013, 52, 83618372.

[51] P. C. Rodrigues Pinto, E. A. Borges da Silva, A. E. Rodrigues, Ind. Eng. Chem. Res. 2010, 50, 741748.

[52] G. Wu, M. Heitz, E. Chornet, Ind. Eng. Chem. Res. 1994, 33, 718-723.

[53] J. Villar, A. Caperos, F. Garcia-Ochoa, Wood Sci. Technol. 2001, 35, 245-255.

[54] J. Zhang, H. Deng, L. Lin, Molecules 2009, 14, 2747-2757.

[55] H. Deng, L. in, S. Liu, Energ. Fuel, 2010, 24, 4797-4802.

[56] M. Goral, B. Wisniewska-Goclowska, A. Maczynski, J. Phys. Chem. Ref. Data 2006, 35, 1391-1414.

[57] S. G. Santos, A. P. Marques, D. L. Lima, D. V. Evtuguin, V. I. Esteves, Ind. Eng. Chem. Res. 2010, 50, 291-298.

[58] S. Crossley, J. Faria, M. Shen, D. E. Resasco, Science 2010, 327, 68-72. 
[59] I. Golovanov, S. Zhenodarova, Russ. J. Gen. Chem. 2005, 75, 1795-1797. 
TOC

The conversion in water/octanol mixtures was more effective than conversion in a monophasic system at corresponding conditions showing the proof of concept for biphasic depolymerization (BPD). Conditions maximizing the yields for vanillin were $\mathrm{T}=170^{\circ} \mathrm{C}, \mathrm{t}=60 \mathrm{~min}$, and $\mathrm{pO} 2=5 \mathrm{MPa}$. The presence of the oxidative catalyst ( $\mathrm{CuSO} 4$ ) did not influence the yields measurably. The contributions of oxidation and acidolysis of lignin were assessed to be approx. 60 and $40 \%$, respectively. 


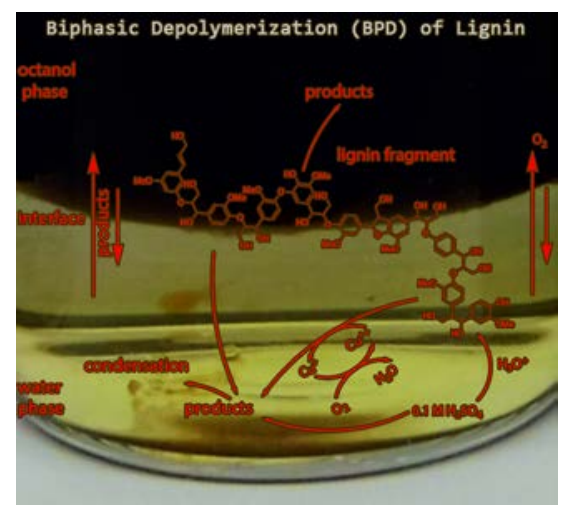

